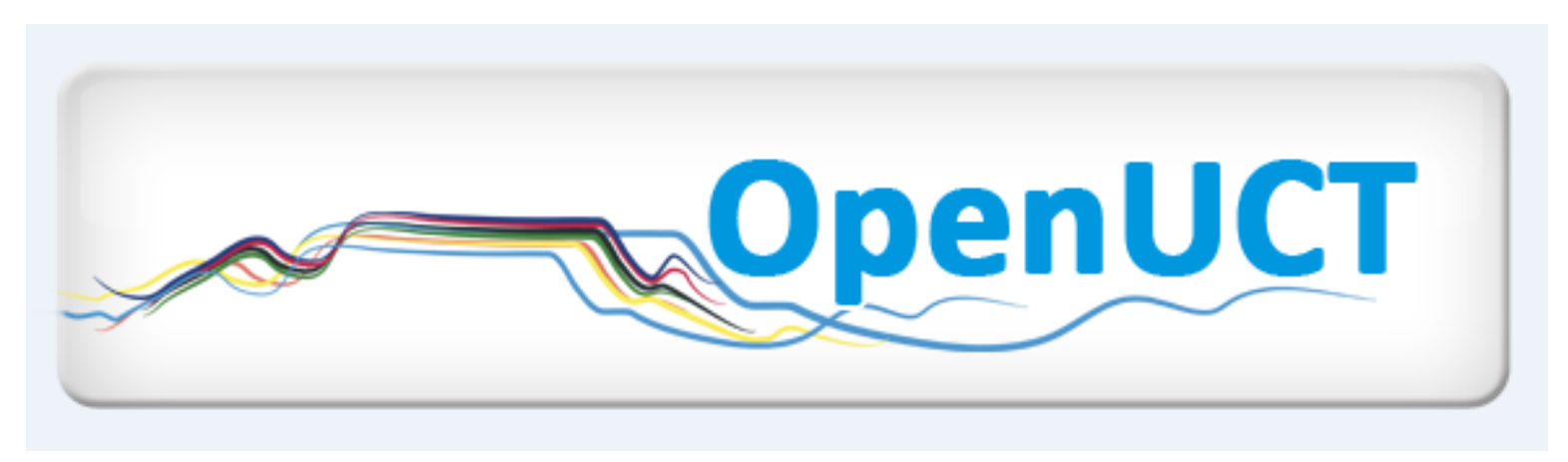

This is the author-approved manuscript version of a journal article published in:

Blackie, M. A. L., Case, J. M. \& Jawitz, J. 2010. Student centredness: the link between transforming students and transforming ourselves. Teaching in Higher Education. 15:6, 637-646, DOI: 10.1080/13562517.2010.491910.

It is made available under the terms of agreement between the author and the journal, and in accordance with the University of Cape Town's Open Access Policy for the purposes of research, teaching and private study. http://www.openuct.uct.ac.za/sites/default/files/UCTOpenAccessPolicy.pdf 


\title{
Student-centredness: the link between transforming students and transforming ourselves
}

\author{
Margaret A.L. Blackie \\ Department of Chemistry and Polymer Science, Stellenbosch University, South Africa \\ Corresponding author. Email: mblackie@sun.ac.za \\ Jennifer M. Case \\ Department of Chemical Engineering, University of Cape Town, South Africa \\ Jeff Jawitz \\ Centre for Higher Education Development, University of Cape Town, South Africa
}

\begin{abstract}
It is widely accepted in the higher education literature that a student-centred approach is pedagogically superior to a teacher-centred approach. In this paper, we explore the notion of student-centredness as a threshold concept and the implications this might have for academic staff development. We argue that the term student-centred in the Rogerian sense implies a focus on the person of the student and is deeply resonant with Barnett's assertion that the emergent being of the student is as important as the development of skills and knowledge. To facilitate transformative learning in higher education an academic must know how to value the person of the student in the learning process. Academic staff development initiatives need to work with the person of the academic and take into account the level of personal development required for each academic to be able to facilitate this kind of learning.
\end{abstract}

Keywords: student-centred; academic staff development; being; transformation

\section{Introduction}

[T]ruly awful teaching in higher education is most often revealed by a sheer lack of interest in and compassion for students and student learning. (Ramsden 1992, 98)

The desirability of 'student-centredness' underpins much contemporary discussion on teaching in higher education, as evidenced in the above quote by Paul Ramsden. This is also reflected in the literature on 'conceptions of teaching' where student- and teacher-centred approaches tend to describe the poles of a spectrum representing how teachers describe their practice (Kember 1997). In the teacher-centred approach the focus is on delivery of material whilst the student-centred approach focuses on how the student understands the material. This characterisation is supported by Kember's (1997) meta-study of 13 empirically based studies on conceptions of teaching which represents these collective findings in a single spectrum, shown in Figure 1.

Studies on conceptions of teaching following Kember's (1997) study generally continue to produce forms of this dichotomy, although some authors argue that 


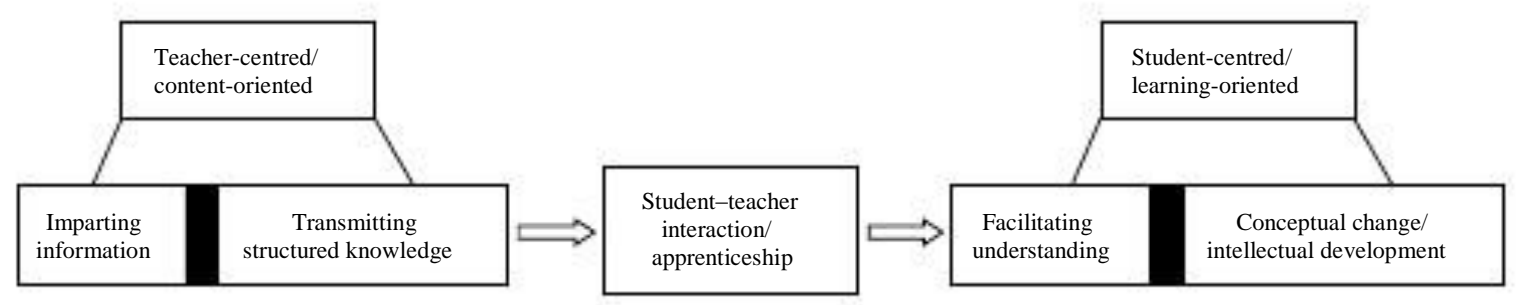

Figure 1. Multiple-level categorisation of conceptions of teaching (Kember 1997, 264).

characterising the dichotomy content vs. learning affords a greater nuance (Postareff and Lindblom-Ylanne 2008). Irrespective of the favoured terminology the vast" majority of authors assert that the student-centred or learner-focused conception of

teaching is the more effective conception of teaching (Akerlind 2003). This is borne out in the findings of Prosser and Trigwell who state that 'university teachers who focus on their students and their students' learning tend to have students who focus on meaning and understanding in their studies, whilst university teachers who focus on themselves and what they are doing tend to have students who focus on reproduction' (Prosser and Trigwell 1999, 142).

In this paper we suggest that student-centred teaching is a threshold concept. Meyer and Land $(2005,372)$ define a threshold concept as a 'new way of understanding, interpreting, or viewing something'. It is usually 'transformative (occasioning a significant shift in the perception of a subject), irreversible (unlikely to be forgotten, or unlearned only through considerable effort), and integrative (exposing the previously hidden interrelatedness of something)' (Meyer and Land 2005,373 ). Student-centred teaching is not just a different style of teaching. It requires that the academic really understands and appreciates the need to pay attention to the students and their learning. It involves a shift from measuring one's success as a teacher by how much of the syllabus is successfully covered to measuring one's success by how much the students actually learn and with what depth of understanding. This requires the academic to be invested in the learning of the students, rather than in the transfer of information, and to be concerned about the actual process of learning happening in the students. In order to appreciate the significance of this mental shift we have found it valuable to return to one of the principle architects of the term 'student-centred learning', Carl Rogers.

\section{Carl Rogers' notion of 'student-centred' learning}

In this section we examine what Rogers intends by 'student-centred learning' (Rogers 1983). The Rogerian term is derived from 'person-centred', which Rogers uses to distinguish the model of therapy that he developed in the 1950s (Rogers 1961). Rogers' education theory developed out of his ideas on personal development which represented a departure from the more established disciplines of psychoanalysis and behavioural therapy. Rogers' approach is fundamentally humanist as he holds an optimistic view of the potential of any human being, in the absence of any significant impeding force, to tend towards psychological health and maturity (Rogers 1961). For Rogers, a student-centred approach begins with the person of the student and aims to provide an environment where the student can become a mature, fully functioning member of society through engaging in learning. The detail of what is 
learnt is important, but it is secondary to this primary aim. It is easy to gloss over the significance of this starting point.

Current notions of 'student-centred learning' might therefore have lost the essence of the Rogerian approach. In this understanding the 'person' of the student is of paramount importance. Rogers' own conception of the implications of this position involves educational institutions functioning in such a way that each student would be supported in following their own interests, and setting their own curricula. In some ways the image of a Rogerian institution is being raised again with the possibilities that technology offers us. On-line course design offers the possibility of students following their own curriculum at their own pace. In such a system the student may well hold far more power and control over what they learn and when they learn it. However, this line of thinking might again fail to honour the heart of Rogers' teaching: for Rogers, the personal relationship between student and teacher provides the essence of the facilitation. In the absence of the personal relationship, such as in programmatic technology-driven curricula, learning is far less meaningful. Again it is important to look at the underlying philosophy and from whence it is derived. For Rogers, the teacher needs three core attributes Á congruence, unconditional positive regard and empathy. Congruence or genuineness is a commitment to the attempt to minimise the disparity between one's espoused life philosophy and operational life philosophy. It requires a high degree of self-knowledge and an openness to new information about oneself discovered through personal reflection and interaction with others. Congruence requires that the face one presents in the classroom is not substantially different from the face one presents in research or in one's family life, indeed, congruence requires that facades are dropped. Uncondi-, tional positive regard is the way in which one views one's students. It is crucial that one is able to value the person of the student regardless of whether they are successful at one's subject or not. This unconditional valuing of the person is necessary for growth. Finally, empathy requires that one pays significant attention to the student and that one can appreciate and really understand their position. The relationship between student and teacher is then a deeply human one which may prove transformative, ideally, for both student and teacher.

\section{Barnett's ontological and epistemological learning}

There is some significant resonance between the Rogerian model of education and the argument that Barnett presents in A will to learn (Barnett 2008). For example, the Rogerian emphasis on the person of the student resembles Barnett's 'being' and the Rogerian notion of congruence is similar to the authenticity described by Barnett (2008). However, Barnett's work is more explicitly based on a philosophical framework informed by Heidegger's notion of 'being'. In A will to learn (2008) Barnett juxtaposes what he terms epistemological learning and ontological learning. $\mathrm{He}$ argues for a view of higher education which values the being of the student (ontological learning), over and above the 'knowledge and skill' based approach (epistemological learning). The process of higher education should be more than an increase in a particular skill set or knowledge area. There should be a fundamental growth in the person of the student. 'What matters supremely is their separate becoming, and their becoming requires the formation and the sustaining of their will to learn' (Barnett 2008, 170). 
However, working ontological and epistemological learning into yet another dichotomy, like those mentioned earlier, is not necessarily helpful in the pursuit of valuing the being of the student. In a context where student employability is a driving force in higher education (Mann 2008), it may not be useful to present a model of learning which requires a significant sacrifice in achieving levels of skill and knowledge in order to prioritise the intangible and unmeasurable quality of 'being'. The use of the concept of embodied learning which points towards an holistic education, may prove more acceptable (Barnett 2008; Mann 2008). 'Embodied learning' refers to knowledge that is gained through a deep approach to learning and results from the personal engagement of the student with the subject matter at hand. For example, a law student engaging with the framework of personal and family law may be changed as a person and this change may have an influence on his relationships with those around him. Meaning making, therefore, is not an abstract idea. Meaning making is impossible outside of the individual and therefore the knowledge gained is 'embodied' knowledge. It is for this reason that Mezirow (1991) suggests that the self-image of the learner should be considered as part of the learning context. A focus on 'being' cannot be considered apart from 'knowing' and 'acting' Á what is learnt, the way in which it is learnt and the way in which it is retained all have an impact on the 'becoming' of the student. To emphasise 'becoming' or 'being' without keeping the content in focus is not necessarily helpful. Hence, epistemological learning and ontological learning should not be held in a false dichotomy.

In Barnett's terms this embodied learning is implicit in his emphasis on the significance of the growing of authenticity in the student. Authenticity does not require originality, but it does require that the knowledge professed by the student is embodied in the student, and is sincerely proposed by the student. Barnett's criterion of sincerity is derived from the validity claims of Habermas. For Barnett a valid knowledge claim must encompass sincerity, truthfulness and appropriateness (Barnett 2008). Of the three conditions, sincerity is situated squarely in the individual. For Barnett, attending to sincerity is a crucial part of the education process, for it is through the sincere endeavour to voice claims that are both true and appropriate that the student uncovers aspects of her true being. In this argument, truthfulness may be understood as the knowledge that is accepted as being accurate by the discipline and appropriateness may also be related to Gee's notion of discourse (Gee 1996), a certain way of acting and being that makes one recognisable as a member of a particular community.

A closer examination of Barnett's elements of a valid knowledge claim, sincerity, truthfulness and appropriateness highlights the challenge in this model of education. Truthfulness and appropriateness are socially constructed, and exist beyond the individual student. Sincerity is the arena over which the student has control. The real difficulty here is that it is almost self-evident that sincerity should be valued in education, and yet we have no way of measuring it. The criterion of sincerity does not require the information to be accurate. However, sincerity requires that the student believes this statement to be accurate to the best of their knowledge, regardless of the limitations of the knowledge set that they hold. After they have discovered their statement to be false they can no longer hold this with sincerity, and thus the claim is invalidated. Sincerity may also imply that the student takes reasonable steps to ensure that their knowledge set is appropriate. For example, the student may not 
apprehend the knowledge fully, but it is reasonable to assume that they have read the appropriate sections in the textbook.

If we are to take the idea of the person of the student seriously, we need to begin to pay attention to the emotional side of education. Knowledge may be emotionally neutral. There is no obvious emotional content to the concept of chemical bonding, for example. However, the manner in which an individual interacts with knowledge is emotionally charged. Barnett uses powerfully emotive terms to describe educational experiences. For example, he uses the phrase 'durable ecstasy' (Barnett 2008, 60) to describe the joy and fulfilment which accompanies finally understanding a difficult concept. This is the kind of deep and transformational experience which occurs when she 'becomes aware that she has understood something that had been posing a challenge or she realizes that she has enacted a set of actions that had been daunting beforehand. She becomes herself and is aware of that new becoming' (Barnett 2008, $60)$. The thing that the student has understood is not insignificant. If the student is studying chemistry the fact that she has come to understand the hybridisation of atomic orbitals, or some such concept, is important. The knowledge is not new, but it is new to her. In understanding it, the knowledge becomes a part of her. She will not return to the former state where she did not understand this concept. It is the crossing of the threshold in the being of the student. As noted above, the ontological becoming is situated within the epistemological becoming. Therefore, the emotional development of the student is not irrelevant to her intellectual development.

\section{The significance of care and empathy}

For Barnett and Rogers, the purpose of higher education is to enable students to 'become themselves': to come to a point where they are able to evaluate their own performance and to appreciate their own giftedness. It is important to recognise that not all students will consciously engage with the notion of 'becoming'. The concept of undergoing personal development during the course of their passage through higher education may seem a poor second to the primary goal of gaining knowledge and developing a particular skill set. However, if we fail to observe that personal transformation is a possible and desirable end to higher education, we will then limit the means to achieve such an end. Dewey (1963) proposes that we need to have the ends in view in order to facilitate education. As such, we need to hold a vision of the potential of each student in order to help, at least some of them, to make significant moves towards becoming their authentic and congruent selves.

The key element which facilitates the transition from a good education to a transformative one is empathy. The idea that empathy is significant in a truly educative process (Dewey 1963) is emphasised by Ramsden (1992) as seen in the opening quote to this paper. Ramsden is suggesting that both an interest in and empathy for students and student learning are necessary components of good teaching. The interest in students and student learning is widely accepted as characteristic of a student-centred approach, however, the empathy for students and student learning is frequently glossed over, if not overlooked entirely.

Barnett (2008) emphasises the significance of uncertainty in the student's experience of higher education. If sincerity is an important requirement of the educative process, then turning in an assignment, sitting an exam, etc. require risk on the part of the student. Not simply risk in terms of the mark and their progress 
through higher education, but risk in terms of self-exposure (Barnett 2008; Mann 2008). Barnett argues that uncertainty must therefore play a role in teaching. If students are asked to engage in such a risky endeavour this should be modelled by the academic in the teaching context (Barnett 2008). To clarify this assertion we would argue that the analogous uncertainty faced by the academic is in the area of research. In research, the academic must find her own voice. She must pursue an area of research and apply the Habermas criteria of validity Á sincerity, truth, truthfulness and comprehensibility (Morrow and Torres 2002). The scale on which the academic is facing these issues of uncertainty is rightly different to that of the student, but the way in which the academic manages her own uncertainty in research will impact her capacity to hold her students in the zone of uncertainty necessary for becoming. This may not be immediately apparent to the students, but the academic's personal engagement with uncertainty will influence the way in which she manages the experience of uncertainty in her students.

Barnett also focuses on the issue of solicitude, that is to say, care for the student. This is perhaps the key area that makes the whole idea of valuing the person of the student seems unmanageable. The sense of personal responsibility implicit in the notion of care when one is dealing with classes of over 100 students is just beyond the imagination of most of us. Here, feminist author Nel Noddings is a useful resource (Noddings 2003). For Noddings, 'The teacher is necessarily one-caring if she is to be a teacher and not simply a textbook-like source from which the student may or may not learn' (Noddings in Goldstein 1999, 659). For Noddings an act of caring is characterised by two elements Á engrossment and motivational displacement. Engrossment requires that one gives the other one's full attention, and motivational displacement requires that one sets aside one's own agenda in order to pay attention to the needs of the other for the space of the encounter. Caring in this understanding does not require that the academic spends hours mulling over the problems of students, but simply that she is present to the student in whatever interaction they have, and that the needs of the student are given greater importance than her own needs during the encounter. Caring in this perspective may not be characterised by any significant emotional affect for the student (Goldstein 1999). This notion of the significance of caring is reiterated by Sarah Mann who writes, 'an ethics of care is founded on respect, welcome and hospitality, openness and listening, empathy, the assertion of hope, and the deferral of absolute knowing through continual inquiry and dialogue' $(2008,141)$. This means that caring begins with a way of viewing the student. The student is a valued human person and part of the task of an academic is to be present to the student, to treat the student with respect, and to make a small contribution towards helping the student to find their own way through the maze of higher education. For Mann, an ethics of caring underpins the dialogical inquiry, through which the purpose of higher education is elucidated. Without intentional care, it is easy to lose sight of real goal of higher education. In Rogerian terms, this is empathy, arguably the cornerstone of higher education.

\section{Implications for academic staff development}

Whilst Barnett's book (2008) offers a powerful vision of the possibilities of higher education, his focus is almost exclusively on the experience of the student. The problem we face is that we are given a vision of how an academic in such a paradigm 
might engage with students, but few clues are given as to how to provide support for academic staff which may result in the sort of 'inspirational teaching' which Barnett deems necessary. Mann goes further than Barnett in describing the elements she deems necessary for an 'institutional framing of learning which promotes vitality and agency, energy and enthusiasm, student resilience and confidence, and the realisation of potential' (Mann, 2008, p. 136). But again, no mention is made of how an institution might promote the development of their academic staff to support this ideal.

There is evidence to suggest that the introduction of academic staff development programmes aimed specifically at improving teaching has had a positive impact (Bamber 2008; Gibbs and Coffey 2004). These programmes have resulted in a wider adoption of student-centred conceptions of teaching Á using the narrower definition exemplified by Kember (1997). However, what we are suggesting here is that the relational component of education should not be overlooked: 'If the recipients of our care insist that "nobody cares," caring relations do not exist' (Noddings 2003, xiv). For the development of higher education institutions that truly value the being of the student, it is necessary that academic staff members feel valued in terms of their own being, not simply their productivity. It requires a valuing of the person of the academic in its fullness, not simply as a useful cog in the mechanism.

We have argued that one of the key elements in facilitating a truly student-centred educative process is empathy. As programmes on teaching in higher education become institutionalised we would do well to question the efficacy of these programmes in developing empathy. For Rogers, the crucial precondition for student-centred learning is that the "leader or person who is perceived as an authority figure in the situation, is sufficiently secure within himself and in his relationship to others that he experiences an essential trust in the capacity of others to think for themselves, to learn for themselves' (1983, 188, emphasis added). In Barnett's (2008) terms the academic is required to hold authenticity in their being. We do not need to look very far in any institution to see that this precondition cannot be assumed. If we ask academics to hold students in a space of vulnerability and uncertainty in which they can embrace their own beings, it is necessary that we create the kind of environment where academics can explore their own vulnerability and uncertainty.

It is common for newly appointed academics to experience 'imposter syndrome' (Young 2005). This may result from an uncertainty about their ability to succeed in the multifaceted task of being an academic or from a sense of alienation, or exclusion from the dominant culture of the institution. Helping academics to deal with their own fears and uncertainties in this regard and to offer a judgement- and evaluationfree environment in which they might explore the true nature of these vulnerabilities seems an obvious way to facilitate a growth in comfort with uncertainty. As newcomers grow in their experience of being academics, the uncertainties and vulnerabilities may become more nuanced, related to particular aspects of their jobs, or to new responsibilities. In a very clear way, the participation in research and the creation of new knowledge require that the academic always retains some level of comfort with uncertainty. If research in higher education institutions is to occasionally breach new paradigms, it requires a level of daring and willingness to risk being wrong. Similarly if we are to embrace new technologies and discover new 
models of teaching, a willingness to fail is imperative. Such risk-taking requires vulnerability and an engagement with uncertainty.

We have argued that student-centred learning is a threshold concept. If this is the case, we must aim for academic staff development programmes that are transformational of the person of the academic. Any lesser objective is likely to result in programmes which fall short of the mark. So the real question that we need to begin to tackle is: how can we facilitate a truly transformational experience of academic staff development? Using a Rogerian perspective to view academic staff development, several key points emerge. The core of student-centred learning requires treating the student as a whole person. Any academic staff member participating in a development programme should cross this threshold. However, the experience of crossing that threshold may well be significantly different for individuals in the same programme. 'Newcomers follow a range of trajectories in the course of their identity construction as academics and their learning is strongly shaped by their histories and individual experiences' (Jawitz 2007, 185). It may be dependent on factors such as personality, experience, academic field, social class or gender. There needs to be the sensitivity to the fact that the perspectives of those from dominated groups might be substantially different to those from dominant groups. Such an academic staff development programme should be transformative, in a discernible, albeit variant, way for all participants and use the diversity of the participating academics to enable both groups to confront their prejudices and biases. If the programme fails to do this it is unlikely to have the impact on the wider university that would be intended. It is only if such programmes enable every participant to discover their unique way of being an academic that the necessary transformation will occur in the way these academics are able to help students find their own paths to being.

In essence, we are suggesting that an academic staff development programme should offer the academic new skills and new knowledge surrounding what it means to be student-centred in teaching in higher education. Such a programme is far more likely to be transformational for the individual academic and therefore potentially for the department and institution if the relational aspect is consciously and deliberately attended to. The legacy of Carl Rogers suggests that one way to achieve this is by taking the time, energy and resources necessary to treat each academic as a whole person, with individual needs, fears, strengths and weaknesses. It is important here to reiterate Rogers' three qualities Á congruence, unconditional positive regard and empathy. It therefore serves us well to work from the presumptions that the vast majority of academics are well-intentioned individuals who enjoy their interactions with students and operate out of a desire to discover knowledge, create knowledge and share knowledge. Furthermore, we should assume that the majority of academics want to live a full, productive and meaningful life in a manner that is authentic to whom they believe themselves to be. It is important to recognise that authenticity is not a state that we achieve, but rather something that we continuously work towards. The reason for this is that the way in which one understands oneself is not static. Every new experience, every new relationship, the gathering of new information all have an impact on the way in which one understands oneself and one's worldview. For an academic, the daily reality of working life stretches one in all these aspects. With each passing year, the academic is introduced to a large number of people, undergraduate students, research students, research peers, etc.; new data and new knowledge are part of the life commitment. Reaching a static state is not desirable, even if it was possible. The search for new knowledge is fundamental to the appeal of academia, and as such the idea of growth, change and evolution is an inherent part of the life of the higher education institution. With this search comes uncertainty, and the level of comfort with uncertainty is enhanced by a supportive environment. 
If we dare to create an academic staff development programme which is truly transformative, it is likely that the academic staff developers themselves will be transformed in the process. Practising unconditional positive regard towards academics, for example, is likely to increase the generosity with which we view our academic colleagues. It is impossible to truly value the being of another without discovering the value of our own being. Consequently, a commitment to truly transformative academic staff development requires a willingness from all of us to change ourselves, and to allow others to change and grow. It demands that we commit ourselves to believing in the best possible image of our fellow academics in order that we can all see the greatest possibilities in our students. It asks us to commit ourselves to engaging with uncertainty in the knowledge that the fear of appearing ignorant is stifling to learning. Re-committing to the ideal of personal development as a fundamental goal of the process of higher education may reignite the passion for learning that, for so many of us, is the true hallmark of academia.

\section{References}

Akerlind, G.S. 2003. Growing and developing as a university teacher: Variation in meaning. Studies in Higher Education 28, no. 4: 375Á90.

Bamber, V. 2008. Evaluating lecturer development programmes: Received wisdom or selfknowledge? International Journal for Academic Development 13, no. 2: 107Á16.

Barnett, R. 2008. A will to learn: Being a student in an age of uncertainty. Maidenhead, Berkshire: Open University Press.

Dewey, J. 1963. Experience and education. New York: Collier Books.

Gee, J.P. 1996. Social linguistics and literacies: Ideology in discourses. Abingdon, UK: Taylor \& Francis.

Gibbs, G., and M. Coffey. 2004. The impact of training of university teachers on their teaching skills, their approach to teaching and the approach to learning of their students. Active Learning in Higher Education 5, no. 1: 87Á100.

Goldstein, L.S. 1999. The relational zone: The role of caring relationships in the coconstruction of mind. American Educational Research Journal 36, no. 3: 647Á73.

Jawitz, J. 2007. New academics negotiating communities of practice: Learning to swim with the big fish. Teaching in Higher Education 12, no. 2: 185Á97.

Kember, D. 1997. A reconceptualisation of the research into university academics' conceptions of teaching. Learning and Instruction 7, no. 3: 255Á75.

Mann, S.J. 2008. Study, power and the university. Maidenhead, UK and New York: Society for Research in Higher Education \& Open University Press.

Meyer, J., and R. Land. 2005. Threshold concepts and troublesome knowledge (2): Epistemological considerations and a conceptual framework for teaching and learning. Higher Education 49, no. 3: 373Á88.

Mezirow, J. 1991. Transformative dimensions of adult learning. San Francisco, CA: Jossey-Bass.

Morrow, R.A., and C.A. Torres. 2002. Reading Freire and Habermas: Critical pedagogy and transformative social change. New York: Teachers College Press.

Noddings, N. 2003. Caring: A feminine approach to ethics \& moral education. Ewing, USA: University of California Press.

Postareff, L., and S. Lindblom-Ylanne. 2008. Variation in teachers' descriptions of teaching:" Broadening the understanding of teaching in higher education. Learning and Instruction 18, no. 2: 109 Á20.

Prosser, M., and K. Trigwell. 1999. Understanding learning and teaching: The experience in higher education. Buckingham, UK and Philadelphia, PA: SRHE and Open University Press.

Ramsden, P. 1992. Learning to teach in higher education. London and New York: Routledge.

Rogers, C.R. 1961. On becoming a person. London: Constable.

Rogers, C.R. 1983. Freedom to learn for the 80's. Columbus, $\mathrm{OH}$ : Charles E. Merrill.

Young, V. 2005. Mentoring for academic careers in engineering. In Proceedings of the PAESM/ Stanford School of Engineering Workshop, ed. E. Riskin. Stanford: Grayphics. 